\title{
"Você é um ambientalista ou trabalha para se sustentar?": trabalho e natureza*
}

Richard White

Em Forks, Washington, uma cidade conhecida por sua atividade madeireira e atingida tanto pelo desmatamento como pela polêmica da coruja-pintada, ${ }^{1}$ pode-se comprar um adesivo de para-choques com a frase: "Você é um ambientalista ou trabalha para se sustentar?". É um insulto curioso, provocador, que sugere outras questôes igualmente interessantes. Por que o ambientalismo parece se opor a trabalho? E como o trabalho acabou por desempenhar um papel táo menor no ambientalismo norte-americano?

Ambientalistas modernos geralmente assumem duas posiçóes sobre o trabalho, ambas igualmente problemáticas. A maioria considera o trabalho produtivo equivalente a destruição. Esses ambientalistas ignoram as formas pelas quais o trabalho é, em si, um meio para o conhecimento da natureza, e ao mesmo tempo celebram as virtudes da diversão e do lazer na natureza. Outros, uma minoria, adotam uma segunda posição: certas formas arcaicas de trabalho, em especial a agricultura camponesa, proporcionariam um caminho para conhecer a natureza. Enquanto o ambientalismo mais tradicional cria uma série de imagens populares que frequente e severamente condenam toda e qualquer forma de trabalho na natureza, esse segundo grupo romantiza certos tipos de agricultura e afirma que o trabalho na terra cria uma conexão com o lugar, o que acabaria por proteger a natureza. No entanto, há uma longa história que contradiz os argumentos segundo os quais o trabalho físico no campo estabelece um vínculo que protege a terra.

Há, sem dúvida, numerosos ambientalistas ponderados que reconhecem as férteis conexôes entre trabalho e natureza. Porém, eles o fazem dentro de uma cultura mais ampla que estimula o divórcio entre essas duas noções. É por demais frequente a mobilização, por parte do movimento ambientalista, de palavras e imagens que ampliam esse abismo. Precisamos

\footnotetext{
${ }^{1}$ A polêmica em torno da coruja-pintada (Strix occidentalis) refere-se a uma batalha legal em torno de extinção dessa espécie em função da atividade madeireira, em meados dos anos 1980. Em 1986, um grupo de ambientalistas reivindicou a inclusáo da espécie na lista de espécies ameaçadas de extinção, o que implicaria proteção legal ao seu habitat e consequentes restriçóes à atividade madeireira realizada no estado de Washington. A inclusão ocorreu finalmente apenas em 1990, após longos e exaltados conflitos. Para detalhes, ver o artigo de ANDRE, Claire; VELASQUEZ, Manuel. Ethics and the Spotted Owl Controversy. Issues in ethics, v. 4, n. 1, Spring 1991. Disponível em: <www.scu.edu/ethics/publications/iie/v4n1/>. Acesso em: 23 abr. 2013. (N.T.)

${ }^{2}$ TIMBER drama hits home in town of forks. Seattle Times, 5 ago. 1994. A14.
}

Tradução - DOI - http://dx.doi.org/10.1590/2237-101X014027012 
reexaminar as conexôes entre trabalho e natureza. Elas formam, talvez, os elementos mais críticos de nossa atual crise ambiental. A postura da maioria dos norte-americanos perante o trabalho evidencia problemas fundamentais com a maneira pela qual concebemos o mundo natural e nosso lugar nele. Ao deixar de examinar e inserir o trabalho na esfera da natureza, os ambientalistas cederam importante "terreno cultural" ao assim chamado wise-use movement. ${ }^{3}$ A perda do "terreno natural" é, depois disso, consequência inevitável. O wise-use movement confunde trabalho real com direitos de propriedade - uma construção social. Ele distorce os interesses legítimos de populaçóes rurais em conservar suas formas de vida e obter o devido valor por seu trabalho, convertendo-os no "direito" especial de grandes proprietários e corporaçôes de manter o mundo natural e o bem público como reféns para seu lucro. Enquanto o ambientalismo se recusar a discutir abertamente questóes sobre trabalho e labor, o "wise use" prosperará e os nossos filhos serão aqueles que, ao fim, sofrerão.

Não se pode evitar questôes sobre trabalho e natureza. A maioria das pessoas passa sua vida no trabalho. Além disso, vários séculos de trabalho humano deixaram marcas indeléveis no mundo natural. De um polo a outro, criadores, fazendeiros, caçadores e operários influenciaram o mundo natural profundamente, logo, não há praticamente lugar algum sem sinais de alteração pelo trabalho humano. $\mathrm{O}$ trabalho que alterou a natureza simultaneamente produziu muito de nosso conhecimento sobre ela. Os humanos conheceram a natureza ao cavar a terra, plantar sementes e colher plantas. Eles conheceram a natureza ao sentir o frio e o calor, ao suar quando escalavam montanhas ou chafurdavam na lama. Conheceram a natureza ao esculpir em madeira e pedra, ao viver com animais, ao alimentá-los e matá-los. Os humanos aliaram sua própria energia à energia das correntes de água e vento. A energia física usada por humanos para mover-se no espaço fez com que eles entendessem o significado de distância, como algo além de uma mera abstração. Humanos puxaram, empurraram, carregaram e caminharam, ou se apropriaram da energia de animais, da água e do vento para fazer todas essas coisas. Eles obtiveram um conhecimento corporal do mundo natural.

O ambientalismo contemporâneo desconsidera a importância desse trabalho. Muitos ambientalistas desdenham e desconfiam daqueles que trabalham na natureza da maneira mais evidente. Ambientalistas terminaram por associar trabalho - particularmente o trabalho manual pesado, o trabalho de colarinho azul — a degradação ambiental. Isso acontece seja quando pensam o trabalho realizado em florestas, no mar, em uma refinaria, em uma usina química, em uma fábrica de celulose, no campo de um fazendeiro ou na pastagem de um rancho. Ambientalistas geralmente imaginam que, no momento em que as pessoas que fazem coisas encerram seu dia de trabalho, a natureza está mais pobre. A natureza parece

\footnotetext{
${ }^{3} \mathrm{O}$ "wise-use movement", ou "movimento pelo uso racional", ganhou dimensôes nacionais no campo político norte-americano ao longo do mandato do presidente Ronald Reagan. Tratava-se de um movimento favorável às plenas prerrogativas de uso da propriedade privada, confrontando o movimento ambientalista que frequentemente reivindicava limitações a estas em favor da conservação e proteção ambiental de espécies e ecossistemas. Para detalhes, ver a seção "Wise Use" no sítio do Center for the Defense of Free Enterprise: $<$ www.cdfe.org/center-projects/wise-use/>. Acesso em: 23 abr. 2013. (N.T.)
} 
mais segura quando protegida do trabalho humano.

Essa desconfiança em relação ao trabalho, sobretudo o trabalho manual pesado, contribui para uma maior tendência a definir humanos como extrínsecos à natureza e a enquadrar as questóes ambientais de forma que pareça ser necessário escolher entre humanos e natureza. A “Terceira Guerra Mundial”, tal como afirma Andy Kerr, do Oregon Natural Resources Council, “é a guerra contra o meio ambiente. A má notícia é: o ser humano está ganhando” ‘ Nesta guerra, a arma dos humanos é o trabalho. É a atividade madeireira, a criação de gado e a pesca, é a mineração e a indústria. Ambientalistas, é claro, também trabalham, mas geralmente não realizam trabalhos manuais pesados, e raramente pensam mais profundamente sobre seu próprio trabalho e a relação deste com a natureza.

Assim como Kerr, a maioria dos norte-americanos celebra a natureza como o mundo das coisas originais. E a natureza pode ser de fato o mundo que nós não fizemos — o mundo das plantas, animais, árvores e montanhas —, mas os limites entre esse mundo da natureza e o mundo do artifício, o mundo das coisas que fizemos, já não são mais tão nítidos. As vacas e plantaçóes que criamos, os campos que cultivamos e os genes que modificamos são naturais ou não? São eles natureza ou artifício? Nós buscamos a pureza de nossa ausência, mas em todo lugar encontramos nossas impressões digitais. São nossos próprios corpos e nosso trabalho que em última instância embaralham as barreiras entre o artificial e o natural. Mesmo hoje nós interferimos no material genético de nossos corpos e dos de outros seres vivos, alterando o design de espécie. Não podemos compreender de fato a natureza sem também compreender nosso próprio trabalho, nossos próprios corpos, nosso próprio trabalho corporal.

Entretanto, nas concepçóes atuais sobre as relações humanas com a natureza, há pouco espaço para essa reconciliação. A natureza se tornou um lugar para diversão e lazer dos seres humanos. Conservar uma floresta secular ou criar uma reserva natural é, certamente, uma vitória para algumas das criaturas que vivem nesses espaços, mas também é na mesma medida uma vitória para mochileiros e uma derrota para madeireiros. É uma vitória do lazer e uma derrota do trabalho.

Trabalho e diversão estão conectados, mas as diferenças são significativas. Tanto o nosso trabalho como nossa diversão, como escreveu a linguista Elaine Scarry, implicam uma extensão de nossos corpos sensíveis no mundo externo. Nossas ferramentas, os produtos de nosso trabalho, se tornam extensões de nós mesmos. Nossas roupas são extensôes de nossas peles; nossos martelos são extensões de nossas mãos. Estender nossos corpos no mundo de tal maneira é algo que transforma esse mundo, mas as mudanças são certamente mais óbvias quando resultam do nosso trabalho do que do nosso lazer. As ferramentas de um madeireiro expandem seu corpo até o contato com as árvores, e através dessa extensão ele sabe como a textura das cascas e da madeira dessas árvores varia e se diferencia; ele sabe como elas chei-

\footnotetext{
${ }^{4}$ DIETRICH, William. The final forest: the battle for the last great trees of the Pacific Northwest. Nova York: Simon and Shuster, 1992. p. 209.
} 
ram e como caem. O preço de seu conhecimento é a morte de uma árvore. 5

Ambientalistas muitas vezes passam a impressão de ser arrogantes, convencidos e privilegiados porque eles tão prontamente se permitem identificar natureza com lazer, tornando-a por definição o lugar que humanos visitam e não onde trabalham, permanecem ou vivem. Assim, ambientalistas têm muito a dizer sobre natureza e lazer e pouco a dizer sobre humanos e trabalho. Caso o mundo fosse, de fato, tão distintamente dividido entre os domínios do trabalho e do lazer, dos humanos e da natureza, não haveria problema. Os ambientalistas poderiam então fiscalizar os limites desses domínios e manter claras as categorias. Mas tais dualismos são difíceis de manter; as fronteiras não são tão nítidas. E então os ambientalistas podem parecer uma versão ecológica do Immigration and Naturalization Service, ${ }^{6}$ ou seja, guardas de fronteira em uma causa socialmente duvidosa, moralmente ambígua e definitivamente perdida.

Coloquei esta questão em termos tão ásperos não por me opor ao ambientalismo (ao contrário, eu me considero um ambientalista), mas precisamente porque penso que o ambientalismo deve ser um elemento básico em qualquer tentativa coerente de abordagem dos problemas sociais, econômicos e políticos que os norte-americanos enfrentam nesse fim de século. Os ambientalistas devem se reconciliar com o trabalho, porque seu impacto é tão amplo, e também porque o trabalho, em si, oferece tanto um meio fundamental de conhecer a natureza como talvez a nossa mais profunda conexão com o mundo natural. Se a questão do trabalho for deixada para os inimigos do ambientalismo, ou seja, para movimentos como o "wise-use", com sua devoção estreita a interesses privados, então o trabalho será simplesmente reificado no sentido de propriedade e direitos de propriedade. Caso os ambientalistas isolem o trabalho, retirando-o da natureza, caso criem um conjunto de dualismos no qual trabalho pode apenas significar a ausência da natureza e no qual natureza pode apenas significar o lazer humano, isto empobreceria tanto humanos como não humanos. Pois sem uma aptidão para reconhecer as conexôes entre trabalho e natureza, os ambientalistas chegarão a um ponto em que serão considerados triviais e superficiais, e seus assuntos, politicamente dispensáveis.

\footnotetext{
${ }^{5}$ Sobre madeireiros e conhecimento, ver ibid., p. 39.

${ }^{6}$ O Immigration and Naturalization Service (Serviço de Imigração e Naturalização) foi, até 2003, o órgão responsável nos Estados Unidos pela plena inserçáo de indivíduos estrangeiros na obtençáo e no reconhecimento da cidadania norte-americana. Para detalhes, ver: <www.uscis.gov/portal/site/uscis >. Acesso em: 2 set. 2013. (N.T.)
} 
Devido às propensóes dos ambientalistas a exagerar os limites e a conceber humanos e natureza como adversários em uma luta feroz, qualquer tentativa de enfatizar a importância do trabalho precisa começar pelo desmonte de tais barreiras e pela ênfase nas conexóes humanas com a natureza. $\mathrm{O}$ trabalho já teve em outros tempos o fardo de nos conectar à natureza. Ao passar esse fardo para as várias formas de divertimento que nos levam de volta à natureza, os norte-americanos transformaram fardo em lazer. E o divertimento não pode suportar esse peso. O trabalho implica uma forma de uso do corpo, uma interação com o mundo que são bem mais intensas do que as que ocorrem na diversão. Trabalhamos para viver. Não podemos parar. Já a brincadeira, que pode ser tão sensorial quanto o trabalho, não nos leva a mergulhar tão profundamente no mundo. Na diversão, podemos parar e recomeçar.? Um jogo interrompido no fim das contas não significa nada. Não há nada essencialmente perdido quando a recreação é interrompida ou abandonada. $\mathrm{O}$ trabalho interrompido, por outro lado, tem consequências.

Não é por acaso, portanto, que o lazer que nos leva a uma aproximação maior com a natureza seja justamente aquele que mimetiza o trabalho. Nossa diversão na natureza é, frequentemente, uma forma disfarçada de trabalho manual. Ambientalistas como eu tornam-se mais conscientes da natureza quando viajam como mochileiros, escalam montanhas e esquiam. Nestes momentos estamos profundamente conscientes de nossos corpos. O trabalho realizado por nossos corpos nos informa a textura da neve, das pedras e do solo. Percebemos o chão íngreme, notamos a chuva, o tempo e nos preocupamos com suas variaçôes. Estamos alertas àquilo que nos cerca; temos de ler na paisagem onde encontrar água e abrigo. Sabemos onde o chão é macio ou duro. Conhecemos — alguns melhor do que outros — os hábitos dos peixes, pois queremos matá-los e comê-los. Os momentos mais intensos de nosso lazer na natureza acontecem quando este parece ser táo importante quanto o trabalho: quando se agarrar às pedras numa escalada é crucial; quando estamos caminhando há quatro dias numa trilha e a comida está acabando; quando as corredeiras podem virar nosso barco. Não é de se surpreender que busquemos na natureza riscos cada vez mais extremos. Tentamos fazer do lúdico algo táo relevante quanto o trabalho, como se nossas vidas dependessem disso. Tentamos conhecer, através do jogo e do lazer, o que os trabalhadores, nas florestas, nos campos e nas águas, conhecem através do trabalho.

Essa confusão entre trabalho e diversão, a ideia de um trabalho verdadeiro segregado da natureza e a depreciação do labor moderno são fenômenos complicados. Entre as origens da confusão, há duas convicçóes amplamente difundidas e compartilhadas por muitos norte-americanos. A primeira é a de que a relaçáo original do ser humano com a natureza era uma relação de lazer, e que os primeiros homens brancos na América do Norte teriam vislumbrado e brevemente compartilhado tal relação. A segunda (não totalmente compatível com

\footnotetext{
${ }^{7}$ SCARRY, Elaine. The body in pain: the making and unmaking of the world. Nova York: Oxford University Press, 1985. p. 82.
} 
a primeira) é a de que a "serpente no paraíso" foi a máquina. A sedução da máquina afastou os humanos das possibilidades benéficas que o trabalho na natureza uma vez possuíra. Essas duas visôes precisam ser examinadas criticamente.

Em tese, ainda percebemos traços de uma relação primordial, mais antiga e apropriada, entre humanos e natureza, assim como está explícita na primeira convicção, conectando natureza e lazer, quando partimos para nossas próprias incursóes em florestas, parques nacionais e reservas naturais. Ao promover essa crença em uma conexão entre natureza e lazer, perdemos de vista os modos pelos quais humanos conheceram o mundo natural por meio do trabalho.

Para sustentar a ideia de uma relação original com a natureza, na América do Norte, que antecederia o trabalho, escritores ambientalistas contemporâneos - e, creio eu, muitos ambientalistas - contam histórias como se a diversão oferecesse um contato primal e prístino com a natureza, que o trabalho destruiu. Na prática, os textos ambientalistas populares retomam uma velha história judaico-cristã. $\mathrm{O}$ trabalho seria consequência da queda do homem. No começo dos tempos, ninguém trabalhava. No começo dos tempos, havia harmonia e nenhum vestígio humano na paisagem. Essa é, também, a história contada nas visitas a parques e reservas. Assim, dizemos, é como deve ter parecido ao primeiro homem branco: o mítico primeiro homem branco cuja chegada marca não apenas mudanças específicas, mas o próprio início da mudança. Equiparamos nossas açôes nesses espaços às açôes de figuras históricas emblematicamente ligadas à natureza, e comparamos o trabalho delas aos nossos jogos na natureza.

O primeiro homem branco é, a meu ver, uma figura crítica em nossa confusão sobre trabalho e natureza. Somos solidários aos povos indígenas, mas não os levamos a sério; não os reconhecemos como capazes de provocar mudanças. Homens brancos geralmente atribuem a certos povos não brancos um conhecimento "espiritual" ou "tradicional" que seria atemporal. Não se trata de algo adquirido mediante trabalho ou esforço; tampouco de conhecimento contingente em um mundo contingente. Na América do Norte, os homens brancos são os portadores do pecado original ambiental, pois somente eles são reconhecidos como capazes de trabalho. Porém, de acordo com a mesma linha de raciocínio, também são os únicos verdadeiros agentes da história. É por isso que nossa adulação (visto que é essa, geralmente, a intenção) dos povos "mais simples" é um ato de imensa condescendência. Em um mundo moderno definido pela mudança, os homens brancos são descritos como os únicos seres que fazem diferença.

Ao escrever sobre o primeiro homem branco, autores ambientalistas não estão apenas narrando uma história. Esses relatos se apresentam como história, quando na verdade são apenas contos sobre o paraíso antes do trabalho. Ao longo das últimas duas décadas, historiadores produziram um respeitável conjunto de trabalhos sobre seres humanos e o meio ambiente na América do Norte, que estuda como os povos indígenas modelaram o mundo 
natural em que viveram. ${ }^{8}$ Porém, de uma maneira geral, essa literatura ou não penetrou nas concepçóes populares acerca da natureza ou foi desprezada. $\mathrm{O}$ primeiro homem branco sempre entra em um paraíso intocado. O primeiro homem branco também deve ser, sempre, um homem branco. Caçadores e comerciantes métis franceses penetraram e se estabeleceram no Oeste norte-americano muito antes de os primeiros homens brancos, de maior fama, ali chegarem, mas tendem a desaparecer dos relatos. Mestiços que, por seu trabalho, entram em uma região natural modificada não sustentam com o mesmo impacto o roteiro do maravilhamento perante um mundo anterior ao trabalho.

Os mais celebrados "primeiros homens brancos" ainda são Lewis e Clark? e Daniel Boone. ${ }^{10}$ Daniel Boone é o homem branco na narrativa de Wendell Berry. ${ }^{11},{ }^{12}$ Já Bill McKibben $^{13}$ faz referência a Lewis e Clark, assim como o faz Philip Shabecoff, ${ }^{14}$ um ótimo jornalista ambiental. Em A fierce green fire, sua recente publicação sobre a história do movimento ambientalista, Shabecoff refaz a trajetória de seu "primeiro homem branco" através de terras "não transformadas por humanos". ${ }^{15} \mathrm{O}$ último dos "primeiros homens brancos" foi Bob Marshall, que, imitando deliberadamente Lewis e Clark, é frequentemente citado por ter chegado ao que teriam sido as últimas áreas da América do Norte nunca antes vistas por seres humanos. Mas a a parte central da Serra de Brooks, explorada por Marshall no Alasca,

\footnotetext{
${ }^{8}$ Para um inventário desta literatura, ver: WHITE, Richard; CRONON, William. Ecological change and Indian-White relations. In: WASHBURN, Wilcomb (Ed.). History of Indian-White relations. Washington, DC: Smithsonian Institution, 1988. p. 417-429. (Handbook of North American Indians, v. 4, ed. William Sturtevant). Para um ensaio bibliográfico, ver: WHITE, Richard. Native Americans and the environment. In: SWAGERTY, W. R. (Ed.). Scholars and the Indian experience: critical reviews of recent writing in the social sciences. Bloomington: Indiana University Press, 1984. p. 179-204.

${ }^{9}$ Meriwether Lewis (1774-1809) e William Clark (1770-1838) foram os comandantes da primeira expedição norte-americana a cruzar completamente a porção oeste do território dos Estados Unidos. A expedição, concebida pelo presidente Thomas Jefferson, foi realizada entre maio de 1804 e setembro de 1806. (N.T.)

${ }^{10}$ Daniel Boone (1734-1820) foi um explorador norte-americano, conhecido principalmente por suas incursôes pela atual região do estado de Kentucky. (N.T.)

${ }^{11}$ Wendell Berry, fazendeiro e poeta norte-americano, é autor de $A$ continuous harmony: essays cultural \& agricultural (Nova York: Harcourt Brace, 1972), A world lost (Washington, DC: Counterpoint, 1996) e The way of ignorance and other essays (Washington, DC: Shoemaker \& Hoard, 2005). Para detalhes, ver: <www. wendellberrybooks.com/>. Acesso em: 5 mar. 2013. (N.T.)

${ }^{12}$ BERRY, Wendel. The journey's end. In: BERRY, Wendel. Recollected essays, 1965-1980. Nova York: North Point Press, 1993. p. 259-262.

${ }^{13}$ Bill McKibben é um ambientalista, jornalista e escritor norte-americano. Destaca-se, dentre suas publicaçôes, The end of nature (Nova York: Anchor Books, 1989), tido como um dos primeiros livros sobre mudanças climáticas direcionados a um público amplo. Além disso, publicou, dentre outros, The age of missing information (Nova York: Plume, 1992) e Deep economy: the wealth of communities and the durable future (Nova York: Henry Holt \& Company, 2007). Para detalhes, ver: <www.billmckibben.com/bio.html>. Acesso em: 5 mar. 2013. (N.T.)

${ }^{14}$ Philip Shabecoff é um jornalista norte-americano especialista em jornalismo ambiental, reconhecido sobretudo por sua atuação no The New York Times. Para detalhes, ver: <http://topics.nytimes.com/topics/reference/timestopics/people/s/philip_shabecoff/>. Acesso em: 5 mar. 2013. (N.T.)

${ }^{15}$ SHABECOFF, Philip. A fierce green fire: the American environmental movement. Nova York: Hill and Wang, 1993. p. 23.
} 
fora habitada pelos nunamiut no século XIX, que ali retornaram na década de 1940. Dificilmente as áreas pelas quais Marshall vagou não tinham sido visitadas previamente. ${ }^{16}$

Esses "primeiros homens brancos" são em si figuras históricas certamente fascinantes e de grande apelo, mas meu problema com eles é enquanto figuras culturais construídas pelo ambientalismo. Eles são criados como observadores de um mundo natural, de acordo com McKibben, "tal como existiu fora da história humana." ${ }^{17}$ Mas não é a natureza o que existe fora da história humana, e sim o primeiro homem branco, uma vez que os escritores ambientalistas descrevem não a forma como esses viajantes realmente enxergaram o mundo natural, mas sim como nós o teríamos visto se estivéssemos em seus lugares. Nessa construção, os primeiros homens brancos viajam e se maravilham na natureza intocada pelo trabalho. $\mathrm{O}$ breve relato de Shabecoff em $A$ fierce green fire é um exemplo típico. Ele cita uma passagem do diário de William Clark louvando a vista de "uma terra longínqua, distante do mundo civilizado". Shabecoff reconhece um "leve impacto" no meio ambiente causado pelas introduçóes europeias de cavalos e armas, mas reitera o quanto o continente era "intocado por humanos". Lewis e Clark servem tanto para revelar o continente intocado como para deflagrar sua destruição. ${ }^{18}$

Entretanto, essa não é a mais provável ou convincente interpretação do que Lewis e Clark viram e fizeram. Eles estavam, antes de mais nada, bastante cientes de que se moviam por paisagens onde o trabalho humano havia alterado a natureza. Lewis e Clark descreveram indígenas praticando agricultura, caçando, pescando e pastoreando seus animais. A viagem de ambos em direção ao Oeste foi marcada por incêndios provocados por indígenas, com o intuito de transformar a paisagem, influenciar o movimento dos animais ou comunicar sinais uns aos outros. ${ }^{19}$ Lewis e Clark descreveram uma paisagem que, como sabemos - em parte devido a seus relatos - estava já em meio a um processo de conturbada mudança que resultava de trabalho humano. ${ }^{20}$

Lewis e Clark tampouco passaram muito do seu tempo absortos pela beleza sublime do que viram. Não eram cegos à beleza do mundo, mas esta era simplesmente uma característi-

\footnotetext{
${ }^{16}$ Para detalhes sobre Marshall como primeiro ser humano na área, ver MCKIBBEN, Bill. The end of nature, op. cit. p. 53. Para Nunamiut, ver CATTON, Ted. Inhabited wilderness: the making of Alaska's National Parks (Ph.D. diss.) — University of Washington, Washington, 1994. p. 174-212.

${ }^{17}$ MCKIBBEN, Bill. The end of nature, op. cit. p. 52.

${ }^{18}$ SHABECOFF, Philip. A fierce green fire, op. cit. p. 22-24.

${ }^{19}$ MOULTON, Gary E. (Ed.). The journals of the Lewis \& Clark expedition. Lincoln: University of Nebraska Press, 1986-1987. v. 2-4. Registros de 23 jul. 1804, v. 2, p. 415; 15 ago. 1804, v. 2, p. 483; 17 set. 1804, v. 3, p. $80 ; 23$ set. 1804 , v. 3, p. 104; 29 out. 1804 , v. 3, p. $210 ; 6$ mar. 1805, v. 3, p. $309 ; 28$ maio 1805, v. 4, p. $237 ; 20$ jul. 1805 , v. 4 , p. $407 ; 25$ jul. 1805 , v. 4 , p. 428.

${ }^{20}$ Um dos melhores exemplos é a literatura recente sobre o declínio do bisão. FLORES, Dan. Bison ecology and bison diplomacy: the Southern Plains from 1800 to 1850. Journal of American History, Bloomington, v. 78, p. 465-485, 1991. Eu também analisei o papel dos indígenas em remodelar o ambiente em WHITE, Richard. The roots of dependency: subsistence, environment, and social change among the Choctaws, Pawness, and Navajos. Lincoln: University of Nebraska Press, 1983.
} 
ca observável: “a terra continua fértil e bela”, Lewis anotou em uma típica passagem. ${ }^{21}$ Mesmo quando se comovem, como nas ravinas do Missouri, por "cenas de encanto visionário", o que absorve muito mais a atenção de Lewis e Clark é o trabalho extenuante de seguir rio acima. $^{22}$ É esse trabalho que lhes oferece o mais pessoal, íntimo conhecimento da região. Quando descrevem o trabalho, seu estilo se torna expansivo e detalhado. Eles não estão apenas vendo a terra. Eles a estão sentindo; estáo literalmente emaranhados nela. Assim descrevem Clark e Lewis sua luta para atravessar as ravinas do Missouri. Primeiramente Clark: "nós partimos, e prosseguimos com grande labor (...) \& as margens eram tão enlameadas e escorregadias que os homens mal poderiam andar". A terra próxima ao rio, a terra sobre a qual eles pelejaram, é "em boa parte rocha; e terra rica, a pouca chuva que caiu leva a terra, até a profundidade em que está molhada, a deslizar para o rio e para o fundo". Em seguida, Lewis:

os homens são forçados a permanecer imersos na água, até as axilas, e a água está ainda muito fria, e tão frequentes são estes momentos [onde há obstruçóes no rio] que eles passam um quarto de seu tempo na água; além disso, as margens e os bancos pelos quais eles são obrigados a passar ao longo do caminho são tão escorregadios e a lama tão grudenta que eles não podem usar seus mocassins, e seguem nessa situação carregando o fardo pesado de uma canoa e caminhando por vezes por várias centenas de metros sobre pedras pontiagudas que rolam dos despenhadeiros e adornam as margens do rio; em poucas palavras, seu trabalho é incrivelmente doloroso $(. . .)^{23}$

$\mathrm{O}$ que mais profundamente ligou esses homens à natureza, aquilo sobre o que escreveram de maneira mais vívida, foi o trabalho: trabalho pesado, enervante, exaustivo. $\mathrm{O}$ esforço do corpo revelou que a natureza era fria, enlameada, brusca, tenaz, escorregadia. Muitos outros adjetivos também descreveram o contato imediato e tangível entre o corpo e o mundo não humano. Os escritores ambientalistas deliberadamente suprimiram estes trechos de suas obras e os substituíram pela narrativa do "primeiro homem branco", em mero lazer extenuante ou observação respeitosa.

Desta forma, ocultamos o trabalho dos primeiros homens brancos. Igualamos o seu trabalho à nossa diversão. Implicitamente, presumimos que as expediçóes dos primeiros homens brancos devem ter sido como uma longa trilha ou caminhada pelo Oeste. Entretanto, eles não adquiriram conhecimento sobre a natureza pela diversão; eles aprenderam e se relacionaram com a natureza através do trabalho. E nós involuntariamente reconhecemos isso quando fazemos de nossos jogos a mímica de seu trabalho.

\footnotetext{
${ }^{21}$ Registro de 6 maio 1805. In: MOULTON, Gary E. (Ed.). The journals of the Lewis \& Clark expedition, op. cit. v. 4, p. 117.

${ }^{22}$ Registro de 31 maio 1805. Ibid., p. 231.

${ }^{23}$ Registros de 30 e 31 maio 1805. Ibid., p. 223-225.
} 
Este ocultar do conhecimento obtido através de trabalho é típico de certa abordagem ambientalista do trabalho, mas o verdadeiro papel do trabalho pode ser revelado facilmente. Exemplos de conhecimento humano da natureza adquiridos mediante o trabalho se mostram prontamente quando queremos vê-los. Por milênios, humanos conheceram animais principalmente por meio do trabalho. $\mathrm{O}$ trabalho deu às pessoas que treinaram e trabalharam com animais um conhecimento especial sobre eles. "Há algo em um cavalo que não é um mero mecanismo, sabe”, explicou Albert Drinkwater, um carroceiro da Columbia Britânica; "um cavalo não irá trabalhar do mesmo jeito para todo mundo. Ele vai trabalhar para um homem e vai fazer de conta que empurra para outro". "Os próprios cavalos se tornaram (...) parte do homem que os conduzia." ${ }^{24}$ Hoje em dia, os animais que conhecemos mais intimamente são os animais de estimação; eles compartilham nosso lazer, mas não nosso trabalho. Encontramos parcerias de trabalho apenas em alguns lugares exóticos. Um deles é o circo. Lá, o trabalho em conjunto de humanos e animais sobrevive sob a forma de entretenimento.

Circos onde humanos e animais se reúnem para realizar uma tarefa comum são hoje estigmatizados como espaços artificiais ou até mesmo cruéis. Animais que trabalham despertam compaixão, e quase sempre presume-se que sofram abusos. Porém, tal compaixão náo faz sentido no mundo circense descrito por Diana Cooper em seu recente livro, Night after night. Trabalhar intimamente com um animal treinado é, diz ela, conhecer algo não humano, profunda e vividamente. Cooper descreve treinadores como "mergulhados no seu trabalho, concentrados nos animais e seus parceiros humanos e no que eles estão criando todos juntos". ${ }^{25}$ É o treinador "quem, por conhecer Toto, ensinou-lhe o que ele precisa saber". ${ }^{26}$ E o que treinadores aprendem sobre elefantes e cavalos é não apenas algo sobre elefantes e cavalos em geral, mas também um conhecimento profundamente particular sobre cavalos e elefantes como indivíduos. Isso é um conhecimento que possuímos porque temos corpos com os quais trabalhar. Em nossos próprios corpos, nós nos deparamos não com ideias sobre o mundo, mas sim com outros corpos. Confrontamos a intransigente materialidade do mundo em si. Conhecer um elefante ou um cavalo através do trabalho é saber que, por mais amplo que possa ser o seu conhecimento geral sobre cavalos ou elefantes, o que também importa é conhecer certo elefante em particular, em um dado momento específico.

É exatamente esse reconhecimento de como o trabalho oferece não só uma conexão com a natureza como também um conhecimento da mesma que separa uma minoria dos ambientalistas, sobretudo aqueles que compartilham das ideias de Wendell Berry, da depreciação do trabalho, comum entre ambientalistas. Mas essa segunda posição, minoritária, restringe o conceito de "trabalho bom" ao esforço realizado sem máquinas modernas.

\footnotetext{
${ }^{24}$ Citado em RAJALA, Richard. The forest as factory: technological change and worker control in the West coast logging industry, 1880-1930. Labour/Le Travail, Edmond, v, 32, p. 84, Fall 1993.

${ }^{25}$ COOPER, Diane Star. Night after night. Washington, DC: Island Press, 1994. p. 129.

${ }^{26}$ Ibid., p. 135 (grifos do autor).
} 
Baseia-se, em diferentes níveis, naquela segunda convicção, aqui examinada, que possui o ambientalismo contemporâneo sobre o trabalho na natureza. Na realização deste trabalho, pessoas supostamente tiveram em algum momento uma relação mais verdadeira e benéfica com o mundo natural, uma relação que a tecnologia corrompeu. Também supostamente, é o trabalho moderno, e não o trabalho em si, que nos transformou em monstros perigosos. Consequentemente, tanto nossa salvação como a da terra podem ser obtidas pelo retorno a uma época anterior à tecnologia moderna, ou, na narrativa de Shabecoff, antes que as "novas máquinas" degradassem a paisagem. ${ }^{27}$

A demonização das máquinas modernas e a sentimentalização de formas arcaicas de trabalho fazem com que o trabalho seja dividido em, de uma parte, o trabalho relativamente benigno e instrutivo e, de outra, o trabalho moderno e destrutivo. $\mathrm{Na}$ agricultura essa dicotomia se revela em sua forma mais intensa. Muitos, embora não todos, ambientalistas romantizam camponeses, agricultores não ocidentais e mesmo certos agricultores norte-americanos pré-modernos, atribuindo-lhes um conhecimento da terra derivado de seu trabalho. Mas em uma era de grandes agrobusiness mecanizados, em uma terra em que produtores substituíram "fazendeiros", e onde a categoria "fazendeiro" foi eliminada como categoria profissional nos censos, esta atribuição desaparece, e os ambientalistas não mais reconhecem este conhecimento sobre a natureza entre agricultores contemporâneos.

John Berge ${ }^{28}$ não escreve com tais intençôes, mas seus ensaios sobre camponeses e campesinato, em Pig earth ${ }^{29}$ podem ser citados como exemplos de conhecimento campesino. ${ }^{30}$ Nessas comunidades, "trabalhar é uma forma de preservar conhecimento". ${ }^{31}$ Não há camponeses nos Estados Unidos, mas há agricultores que vivem muito este conhecimento camponês da terra. Os agricultores nas montanhas do Novo México, por exemplo, condividiam outrora da vida descrita por Berger.

Jacobo Romero foi um agricultor nas montanhas de Sangre de Cristo, no Novo México. O rio de las Trampas - de fato, pouco mais que um riacho - e Romero são os protago-

\footnotetext{
${ }^{27}$ SHABECOFF, Philip. A fierce green fire, op. cit. p. 29.

${ }^{28}$ John Berger é um ensaísta, crítico de arte e romancista londrino. Suas publicaçóes são diversificadas e estimadas pela crítica, abrangendo não apenas debates de ordem estética mas também o engajamento do autor em relação ao campesinato europeu. Detalhes em: <www.johnberger.org/johnberger.htm>. Acesso em: 5 mar. 2013. (N.T.)

${ }^{29}$ O romance Pig earth, de John Berger, é o primeiro livro da trilogia Into their labours, precedendo as obras Once in Europe e Lilac and flag. (N.T.)

${ }^{30}$ BERGER, John. Pig earth. Nova York: Pantheon, 1979. p. 1-12, 195-213.

${ }^{31}$ Ibid., p. 75.
} 
nistas no comovente River of traps, de William deBuys ${ }^{32}$ e Alex Harris. ${ }^{33}$ Romero conhecia a natureza através do trabalho. Assim como os camponeses de Berger, "incansavelmente comprometidos com a difícil vida na terra”, ele era táo ligado a um lugar particular que retirá-lo de lá teria sido transformar quem e o que ele era. Romero trabalhava sua terra ao longo do rio, e seu trabalho gerava conhecimento que podia ser transmitido a outros. Trabalhar - a forma como se trabalha, como se usa uma pá, como se monta um cavalo - é ao mesmo tempo um conhecimento corporal e um conhecimento social, parte daquilo que Pierre Bourdieu chama de habitus. Tal conhecimento se conecta à experiência física, mas não deriva somente ou, por vezes, sequer diretamente desta. Trabalhar comunica uma história de trabalho passado; essa história é transformada em prática corporal até que pareça simplesmente uma segunda natureza. Esse habitus, esse conhecimento corpóreo, é inconscientemente observado, imitado, adotado, e transmitido em uma dada comunidade. Nosso trabalho na natureza tanto reforça como modifica o habitus. ${ }^{34}$

Felizmente, em River of traps, Bill deBuys e Alex Harris eram estranhos a esse habitus, velhos demais para aprender da maneira usual. Jacobo Romero, portanto, teve de articular verbalmente, explicar e explicitar o que seria de outra forma segunda natureza para alguém da idade deles. Sua primeira e mais reveladora recomendação é "nunca dar descanso para a água", mas sim "colocar cada gota para trabalhar". ${ }^{35}$ Para deBuys e Harris, observar Romero pôr em prática sua assertiva é como observar sua pá se transformar em uma ferramenta de arte. Como um músico que lida com seu instrumento, Jacobo afinava a água, "observando-a e ouvindo-a tal qual um técnico a reparar seus instrumentos, amplificando o fluxo aqui, emudecendo-o ali, ajustando, reparando, reorganizando". ${ }^{36}$ Ele conhecia seus campos e valas precisa e intimamente; ele os conhecia porque trabalhava com eles. Ele sabia como trabalhar a água porque, após anos trabalhando com ela, sabia que "você tem que deixar a água te mostrar o caminho. Espere o tempo que for necessário e, mais cedo ou mais tarde, a água vai te mostrar". ${ }^{37}$

\footnotetext{
${ }^{32}$ William deBuys é um ambientalista norte-americano nascido em Maryland e doutor em civilização americana pela Universidade do Texas, em Austin. É conhecido por publicaçóes como Enchantment and exploitation: the life and hard times of a New Mexico mountain range (Albuqureque: University of New Mexico Press, 1985) e Salt dreams: land and water in low-down California (Albuqureque: University of New Mexico Press, 1999). Detalhes em: <www.williamdebuys.com>. Acesso em: 23 abr. 2013. (N.T.)

${ }^{33} \mathrm{O}$ fotógrafo Alex Harris já publicou diversos livros. Além de River of traps, junto a William deBuys, é reconhecido também por The idea of Cuba (University of New Mexico Press, 2007). Para detalhes, ver: <http:// alex-harris.com/>. Acesso em: 23 abr. 2013. (N.T.)

${ }^{34}$ BOURDIEU, Pierre. Outline of a theory of practice. Cambridge: Cambridge University Press, 1977. p. 78 79; idem,. The logic of practice. Tradução de Richard Nice. Stanford: Stanford University Press, 1990. p. 6679. Bourdieu, no entanto, tem relativamente pouco a dizer sobre a forma através da qual habitus e trabalho realmente se intercalam no mundo natural.

${ }^{35}$ BERGER, John. Pig earth, op. cit. p. 198; DEBUYS, William; HARRIS, Alex. River of traps: a village life. Albuquerque: University of New Mexico Press, 1990. p. 11.

${ }^{36}$ Ibid., p. 23.

${ }^{37}$ Ibid., p. 24.
} 
Wendell Berry é o escritor ambiental que mais cuidadosamente tentou compreender o trabalho tal como feito por Romero ou pelos camponeses de Berger. Berry não é apenas um dos poucos escritores ambientalistas que considera seriamente o conceito de trabalho; ele também efetivamente trabalha em seus próprios campos, buscando uma consistência que impressiona. Mas Berry faz, evidente e propositalmente, de seu próprio trabalho algo arcaico e incomum; ele se vale da energia animal e convida outros a fazer o mesmo. No entanto, esse é um conselho que só pode ser adotado por "agricultores literários". Afinal de contas, é somente a atividade de escritor de Berry que lhe permite praticar, ainda hoje, uma agricultura com cavalos, e não com máquinas. Tal trabalho é como a jardinagem, um caminho muito adotado hoje em dia para uma reconciliação com a natureza. ${ }^{38}$ É admirável; oferece liçôes e insights, mas não garante o sustento. Não é o nosso verdadeiro trabalho no mundo. Os ambientalistas ainda náo reconhecem nos trabalhadores contemporâneos - aqueles que trabalham com máquinas que dependem de mais do que músculos ou vento para gerar sua energia, aqueles que ganham seu sustento com trabalho - a possibilidade de criar conexôes com a natureza e conhecimento a partir dela.

Os avanços que Wendell Berry, Jacobo Romero ou os camponeses de Berger estabelecem para além do desdém generalizado dos ambientalistas pelo trabalho na natureza, em última instância, não levam a lugar algum, pois tais formas de trabalho estáo sempre em vias de desaparecer ou são incapazes de garantir o sustento. Wendell Berry e Jacobo Romero servem apenas como críticos adicionais da agricultura, da atividade madeireira, da pesca, da pecuária e da indústria modernas. Eles não mudam a mensagem básica de que o trabalho moderno é o inimigo da natureza.

A forma pela qual o trabalho moderno se tornou algo alienado da natureza transformou-se, então, no mote para outro conto - como o dos primeiros homens brancos. Ironicamente, essa história é frequentemente relatada pelos próprios trabalhadores. Ela não é racializada, como a história dos primeiros homens brancos, mas é igualmente definida por uma ideia de gênero: ela trata o trabalho e as máquinas como se fossem masculinos ou femininos. Havia, uma vez — assim afirma o conto —, o trabalho verdadeiro e másculo, que exigia habilidade e força e tinha suas raízes no mundo natural. Esse era o trabalho dos camponeses de Berger ou de Jacobo Romero. Mas esse bom trabalho foi, em nossos dias, contaminado por máquinas.

Essa narrativa, assim como a narrativa do primeiro homem branco, usa história sem ser uma história. Em alguns sentidos, certamente, máquinas de fato tornaram supérfluas muitas das práticas dos trabalhadores e os alienaram da natureza. Conforme o trabalho se tornou menos exigente fisicamente, conforme passou a requerer menos conhecimento corporal, os trabalhadores que antes possuíam tais habilidades, tornadas agora irrelevantes pelas máqui-

\footnotetext{
${ }^{38}$ POLLAN, Michael. Second nature: a gardener’s education. Nova York: Delta Trade Paperbacks, 1991. esp. p. 209-238.
} 
nas, sentiram-se roubados de algo valioso. Os antigos madeireiros da baía Coos, em Oregon, por exemplo, desprezam a atividade madeireira atual. $\mathrm{O}$ trabalho deles entre as grandes árvores demandava capacidade de análise, força e horas de esforço extenuante em uma só árvore, podendo tudo ser perdido caso a árvore caísse de maneira errada e se quebrasse. Mas os madeireiros de hoje cortam "árvores que são varetas". Os antigos madeireiros conheciam a madeira de grande porte, ao passo que os madeireiros contemporâneos vêm cortando "até pelo de cachorro ultimamente" ${ }^{39}$ Essa não é, obviamente, a visão dos madeireiros dos dias de hoje, embora eles também prefiram a madeira secular. ${ }^{40}$

No século XIX, bem como no início do século XX, os trabalhadores de colarinho azul consideravam o trabalho físico um símbolo da masculinidade. Eles frequentemente viam as máquinas que rompiam suas conexóes com a natureza como que os emasculando; eles associavam essas máquinas a mulheres. Charley Russel era um vaqueiro que retirava seu sustento do rancho, antes de se tornar um vaqueiro artista. ${ }^{41}$ Ao lamentar o fim do Oeste, ele também chorou a perda de um mundo onde o trabalho na natureza definia a masculinidade. Máquinas que não precisavam de homens de verdade, que podiam ser operadas por mulheres, haviam quebrado o elo entre o trabalho e a natureza.

A invenção tornou as coisas mais fáceis para a homem, mas não fez dele algo melhor. As máquinas não tem músculos. Uma dama com a mão recém-feita pode dirigir um automóvel sem estragar suas unhas pintadas. Mas sente-se atrás de seis cavalos criados ao ar livre com ambas as mãos segurando nas rédeas! Esses são animais feitos por Deus e têm músculos. Para dirigi-los sobre a estrada de uma montanha é preciso ambas as mãos, os pés e a cabeça, e isso não é trabalho de mulher ${ }^{42}$

Um homem fazia trabalho de verdade com "animais feitos por Deus"; uma mulher poderia manejar máquinas "sem estragar suas unhas pintadas". Máquinas associadas a mulheres quebraram uma conexão masculina com a natureza feminina, criando, assim, quase um drama doméstico. Para Russel, as máquinas evidentemente romperam as velhas conexôes forjadas pelo trabalho viril.

Mas essa divisão entre o "bom trabalho" próximo da natureza e o "trabalho ruim", o trabalho das máquinas que alienaram o homem da natureza, não se sustenta em face do escrutínio histórico. Primeiramente, o trabalho arcaico e o trabalho campesino, por todo o

39 ROBBINS, William G. Hard times in Paradise: Coos bay, Oregon, 1850-1986. Seattle: University of Washington Press, 1988. p. 122; para uma descrição sobre trabalho e habilidade, ver RAJALA, Richard. The forest as factory, op. cit. p. 81-82.

${ }^{40}$ DIETRICH, William. The final forest, op. cit. p. 39.

${ }^{41}$ Faz-se referência, aqui, à atividade profissional na qual o vaqueiro executa performances artísticas em rodeios para o grande público, ressignificando práticas outrora vinculadas apenas ao âmbito do rancho. (N.T) ${ }^{42}$ Russell para o amigo Bob, 14 abr. 1920. In: Charles Russel, Catalog: C.M. Russell Museum. Great Falls, Mont.: C.M. Russell Museum, s.d. p. 19. 
conhecimento que geravam, não foram necessariamente gentis para com a terra. Bill deBuys, que trabalha para a Nature Conservancy, admirava profundamente Jacobo Romero e seu trabalho. Foi seu vizinho e trabalhou ao seu lado. Mas não tem nenhuma ilusão no sentido de que tal conhecimento protegeria a terra de danos. DeBuys demostrou o quanto a agricultura de Jacobo e seus vizinhos deterioravam a terra, mesmo conforme seu trabalho criava um conhecimento do mundo natural e forjava com este uma conexão profunda. ${ }^{43}$

Uma conexão com a terra por meio do trabalho cria conhecimento, mas não necessariamente garante proteção para a própria terra. Há uma espécie de romantismo contemporâneo referente a lugares que afirma que aqueles que vivem e dependem de um lugar não trarão danos a ele. Essa versão conservacionista remete à ideia do wise-use movement. Sua versão ambientalista aparece no biorregionalismo ou no trabalho de Wendell Berry. Berry considera que sua capacidade de escrever é dependente do "trabalho do corpo e do chão". ${ }^{44}$ Ele se vê, em grande medida, como pertencente a um lugar. Em partes, sua conexão é oriunda de uma familiaridade profunda com o lugar, mas também vem do seu prazer com o trabalho de recuperar esse lugar manualmente. Ainda assim, ele restaura uma terra que outros, na mesma medida familiarizados com o lugar, destruíram antes dele. Berry escreve como se o trabalho na natureza, o pertencimento a um lugar, trouxessem uma superioridade moral. Tal enraizamento supostamente ofereceria a solução para nossa relação problemática com o mundo não humano. Eu não acho que isto seja necessariamente verdade. ${ }^{45}$ As escolhas não são tâo simples, nem tão extremas. Ambos os trabalhos, seja o destrutivo ou o construtivo, trazem um conhecimento da natureza, sendo o trabalho destrutivo, às vezes, simultaneamente restaurador, como quando cortamos ou queimamos um prado para impedir o avanço destes em área florestal.

Os custos intelectuais, sociais e políticos de nos limitarmos a essas duas atitudes perante trabalho e natureza são imensos. Condenar todo tipo de trabalho na natureza faz com que os ambientalistas, tal como anunciado no adesivo para carros de Forks, sejam tachados de uma classe privilegiada voltada ao lazer. Já o elogio do trabalho arcaico somado à condenação do trabalho moderno os estigmatiza como reacionários excêntricos, indiferentes às realidades do mundo moderno. Ambientalistas recorrem à história para manter suas posiçôes, mas eles transformam a história em meros contos, fábulas.

Nós precisamos superar isto. A escolha entre condenar todo e qualquer trabalho na natureza ou exaltar formas de trabalho em vias de desaparecer é, simplesmente, uma falsa

\footnotetext{
${ }^{43}$ Este ponto é examinado por DeBuys em River of traps e em um trabalho anterior, Enchantment and exploitation: the life and hard times of a New Mexico mountain range. Albuquerque: University of New Mexico Press, 1985. p. 215-326.

${ }^{44}$ BERRY, Wendell. The making of a marginal farm. In: BERRY, Wendell. Recollected essays, op. cit. p. 336; idem. The body and the earth. Ibid., p. 269-326.

${ }^{45}$ BERRY, Wendell. The unsettling of America: culture and agriculture. Nova York: Avon Books, 1978. p. 138140. Para romantismo, ver, por exemplo, idem. A continuous harmony: essays cultural \& agricultural. Nova York: Harcourt Brace Jovanovich, 1972. p. 79.
} 
escolha. Não estou interessado em substituir um romantismo da natureza inviolada por um romantismo do trabalho local. Tampouco estou interessado em denegrir máquinas. Os ambientalistas precisam se reconciliar com o trabalho moderno. O problema não é que o trabalho moderno tenha sido conspurcado por máquinas. As mulheres que realizavam boa parte do trabalho árduo em fazendas norte-americanas, antes da chegada da eletricidade, nunca alimentaram, até onde eu saiba, nostalgia pelo trabalho de bombear e carregar água, lavar roupas em tábuas de zinco ou qualquer coisa que se assemelhe ao que o senador George Norris de Nebraska chamou de "as eternas tarefas punitivas" da vida rural. ${ }^{46}$ Qualquer um que duvide das esperanças de emancipação através das máquinas e do tipo de trabalho na natureza que suscitou tais esperanças deveria ler a literatura acerca da eletrificação rural; essa literatura descrevia, em detalhes gráficos, o tédio e o custo social dessas formas de trabalho. ${ }^{47}$

Reconciliar-se com o trabalho moderno e com as máquinas pressupóe histórias mais complexas e uma análise de como todo trabalho - e não apenas o trabalho de madeireiros, fazendeiros, pescadores e rancheiros - está em interseção com a natureza. A tecnologia, um artefato do nosso trabalho, serve para encobrir tais conexôes. Há, certamente, tecnologias melhores e piores, mas não há tecnologia que nos remova da natureza. Não dá para rejeitar a demonizaçáo da tecnologia como uma fonte própria de degradaçáo para depois aceitar a crença de que um subconjunto de tecnologias nos poupa da necessidade de trabalhar na natureza e, consequentemente, de trazer danos à natureza. Nós já passamos por isto no século XX.

No século XX, a tecnologia se tornou o receptáculo de nossas esperanças e nossos demônios. Boa parte da tecnologia que hoje condenamos foi uma vez portadora das esperanças para uma ligaçấo mais próxima e íntima com a natureza. Com o passar do tempo, a mesma tecnologia transferiu-se de uma categoria para outra. Tecnologias que hoje, com boas razóes, vemos com suspeita por serem prejudiciais ao meio ambiente - barragens hidroelétricas, por exemplo - foram, em outra época, objeto de esperanças ambientais utópicas. Para Lewis Mumford, por exemplo, barragens e eletricidade prometiam uma integraçáo entre humanos e natureza. Mumford via na tecnologia a capacidade de diluir as fronteiras entre humanos e natureza. Os humanos foram "formados pela natureza e [eram] inevitavelmente (...) parte do sistema da natureza". Ele imaginava para o futuro um mundo neotécnico de máquinas orgânicas e "equilíbrio ecológico". 48

Em uma inversão irônica e reveladora, a solução de Mumford — sua tecnologia libertadora, sua união entre humanos e natureza — foi redefinida como um problema. Não apenas porque represas, por exemplo, acabam com o salmão; elas simbolizam a presença de nosso trabalho no meio da natureza. Em boa parte da literatura ambientalista atual, tais fronteiras

\footnotetext{
${ }^{46}$ Norris, citado em WOLLNER, Craig. Electrifying Eden: Portland General Electric, 1889-1965. Portland, Oregon: Historical Society Press, 1990. p. 162.

${ }^{47}$ Ver, por exemplo, BROWN, D. Clayton. Electricity for rural America: the fight for the REA. Westport, Conn.: Greenwood Press, 1980. p. 115-120. (Contributions in Economics and Economic History, n. 29)

${ }^{48}$ MUMFORD, Lewis. Technics and civilization. Nova York: Harcourt, Brace, 1934. p. 256-57.
} 
diluídas são a marca de nossa queda. A natureza, pensam muitos ambientalistas, deveria se encontrar idealmente fora do alcance de nosso trabalho. Mas ao assumir tal posição, os ambientalistas ignoram a forma mediante a qual certas tecnologias ocultam as conexôes de fato existentes entre nosso trabalho e o mundo natural.

A ideia de que uma natureza pura, apartada de nosso trabalho, possa não mais existir pode provocar quase histeria. Bill McKibben elaborou um best-seller, The end of nature, a partir de tal possibilidade. Para McKibben, o aquecimento global foi o golpe final. "Nós transformamos a atmosfera e estamos transformando o clima. Ao transformarmos o clima, fazemos de cada ponto na terra algo artificial, criado pelo homem" . ${ }_{9}$ "Nós privamos a natureza de sua autonomia, o que é fatal para seu significado. A independência da natureza é o seu significado; sem isso, não há nada a não ser nós mesmos". ${ }^{50}$

Cabe ressaltar que a natureza tal como descrevi nesse ensaio é apenas uma ideia. Quando usamos a palavra "natureza", reiteramos uma unidade, um conjunto de relaçôes e uma identidade comum que envolve todas as coisas não criadas por humanos. A natureza é, nesse sentido, puramente cultural. Diferentes culturas produzem diferentes versóes de natureza. Embora a natureza seja apenas uma ideia, ela é diferente de outras ideias em geral na medida em que afirmamos vê-la, senti-la e tocá-la. Em nossos discursos cotidianos, utilizamos a palavra não apenas para descrever a unidade das coisas que não fizemos, mas também para nomear uma qualidade comum - o natural — portada por coisas aparentemente díspares: salmão vermelho, pinheiros e baratas, por exemplo. Quando avistamos pedras, animais ou rios em determinadas paisagens, dizemos que estamos vendo natureza.

McKibben admite que sua natureza é apenas uma ideia, mas isso apenas nos leva a perguntar por que ele ficaria tâo transtornado pelo fim de uma ideia. A resposta, creio eu, é que McKibben, como todos nós, não reconhece de fato na sua vida e prática cotidianas a distinção entre natureza como uma ideia e natureza como o mundo vivo que respira ao nosso redor. ${ }^{51}$ É difícil ler seu The end of nature sem pensar que ele considera nossa construção moderna e ocidental de natureza como algo profundamente congruente com um mundo real que também está terminando. Muitos seres humanos podem, afinal, aceitar facilmente uma mudança de significado em uma palavra. Todos mudamos de ideia em algum momento. Não sofremos com frequência pela perda de velhas definiçóes e ideias. Aquilo do que sentimos saudade são pessoas, animais e paisagens que deixaram de existir. E se McKibben está lamentando somente a perda de uma ideia, então ele é um homem que vive muito mais em sua própria mente do que no mundo natural sobre o qual escreve. É como se ele, mesmo insistindo na distinção entre mães e maternidade, lamentasse a morte de sua mãe, náo, como declara, por ela mesma, mas porque $a$ ideia de maternidade teria, para ele, morrido junto com ela.

\footnotetext{
${ }^{49}$ MCKIBBEN, Bill. The end of nature, op. cit. p. 58.

${ }^{50}$ Ibid.

${ }^{51}$ Ibid., p. 47-49.
} 
Considerando que McKibben está de fato transtornado e náo apenas sendo histriônico, é difícil não suspeitar que aquilo que realmente o transtorna é o fim do que ele reconhece como o mundo natural em si. Trovoadas, cadeias de montanhas e ursos continuam a existir, mas sem poder traçar um limite preciso entre clima, montanhas, animais e plantas de um lado e as consequências de nosso trabalho, de outro, eles deixaram de ser naturais para McKibben, e nós então nos tornamos incapazes de "imaginar que somos parte de algo maior do que nós mesmos". 52

Se a angústia de McKibben for compartilhada por muitos, então a questão de nossa contaminação da natureza é certamente muito séria, pois se é em parte aos efeitos deletérios de nosso trabalho que McKibben se opóe, é em última instância a habilidade que tem nosso trabalho de tocar todos os aspectos do mundo natural, até mesmo o clima, que o consterna. A popularidade do livro de McKibben indica que, para muitos de nós, o significado do mundo depende de fronteiras nítidas, de categorias puras, e da separação entre a natureza e nós mesmos, nossos corpos e nosso trabalho. Isso é, a meu ver, uma reação norte-americana comum diante do mundo moderno, e merece atenção. Essa fixação na ideia de pureza e desconfiança em relação ao nosso próprio trabalho - junto ao nosso a-historicismo cotidiano, displicente, que nos priva de qualquer comprensão sobre como nossos dilemas atuais se desenvolveram - explicam ao menos parte da nossa inabilidade em lidar com problemas ambientais que se acumulam, divisóes sociais incômodas e um crescente desespero em relaçấo a nossas relaçôes com o resto do planeta.

Quando McKibben escreve sobre seu trabalho, ele comenta que seu escritório e a montanha que avista da janela são partes separadas de sua vida. Elas são desconectadas. Em seu escritório ele está no controle; lá fora, não. Para além da janela de seu escritório se encontra a natureza, distante e independente. Essa é uma divisão nítida. O trabalho e a natureza permanecem segregados e claramente distinguidos.

$\mathrm{Eu}$, assim como McKibben, digito em um teclado. Nesse belo dia de junho eu posso ver as montanhas Olímpicas à distância. Assim como McKibben, eu realizo um trabalho moderno. Eu seleciono, ordeno, compilo, analiso e organizo. Meus movimentos corporais se tornam sinais elétricos através dos quais meus dedos interagem com uma máquina. Luzes cintilam em uma tela. Eu despendo pouca energia; não transpiro, ou sinto dores, ou me canso fisicamente. Ao final deste dia, eu não criei um produto tangível; há apenas memórias registradas e codificadas conforme meus dedos tocavam as teclas. Não há sujeira nem morte ou mesmo consciência do trabalho físico quando termino. Árvores ainda crescem, animais ainda pastam, peixes ainda nadam.

No entanto, diferentemente de McKibben, eu não consigo enxergar meu trabalho isolado das montanhas, e sei que meu trabalho não é de fato desencarnado. Se eu me sentasse e digitasse aqui dia após dia, tal como o fazem trabalhadores de escritório, sem intervalos

${ }^{52}$ Ibid., p. 64-65, 83. 
frequentes para espairecer e admirar as montanhas, eu me tornaria dolorosamente consciente do meu corpo. Eu poderia desenvolver lesóes por esforço repetitivo. Meu corpo, a natureza em mim, se rebelaria. As luzes na tela precisam de eletricidade, e essa eletricidade em particular vem das barragens nos rios Skagit ou Columbia. Essas barragens matam peixes - elas alteram os rios que vêm das cadeias de montanhas Rochosas, Cascades e Olímpicas. A eletricidade que produzem depende de grandes ciclos sazonais do planeta: da neve que cai, das águas que degelam, do fluxo dos rios. No fim, esses impulsos elétricos tomarão uma forma tangível no papel que vem das árvores. A natureza, alterada e transformada, está nesta sala. Mas isso está encoberto. Eu digito. Não mato nada. Não toco em nenhum ser vivo. Aparentemente altero somente a tela, e nada mais. Se eu não pensar nisso, posso parecer inofensivo, as montanhas separadas e a salvo de mim tal como as montanhas Adirondacks parecem a salvo de McKibben, conforme ele escreve seus ensaios para o New Yorker. Mas, é claro, o mundo natural mudou e continua a mudar para que eu possa me sentar aqui, assim como muda para permitir que McKibben escreva. Meu distanciamento é uma ilusão. O que está disfarçado é que eu — diferentemente dos madeireiros, fazendeiros ou criadores — não preciso estar diante daquilo que transformo, e então não aprendo nada relacionado a isso. $\mathrm{A}$ conexão que meu trabalho faz flui em apenas uma direção.

Meu trabalho, creio eu, é semelhante ao da maioria dos ambientalistas. Porque parece tão distante da natureza, fica isento do tipo de condenação que o trabalho que acontece lá fora, na "natureza", atrai. Leio regularmente o High Country News, e seus artigos na mesma regularidade denunciam a mineração, a pecuária e a indústria madeireira devido aos danos que eles provocam. E uma vez que os editores do jornal simpatizam com as populaçóes rurais tentando viver na terra, cartas de leitores criticam o jornal por não condenar essas atividades o suficiente. A intenção daqueles que defendem antigas florestas ou denunciam a exploração excessiva de pastagens não é a de denunciar o trabalho físico pesado, mas é isso o que, na prática, os artigos fazem. Há poucos artigos ou cartas denunciando professores universitários, programadores, contadores ou advogados por degradar o meio ambiente, embora eu creia que um só advogado ou contador poderia, em um bom dia de trabalho, ultrapassar com facilidade os esforços de Paul Bunyan. ${ }^{53},{ }^{54}$

A maioria dos humanos precisa trabalhar, e nosso trabalho - todo trabalho realizado por nós - inevitavelmente nos mistura na natureza, o que inclui os lugares que consideramos puros e selvagens. Foram os próprios ambientalistas que, ao identificar natureza com

\footnotetext{
${ }^{53}$ Paul Bunyan é um personagem do folclore norte-americano. Trata-se de um lenhador gigante cujas atividades resultariam na destruição de paisagens naturais. (N.T.)

${ }^{54} \mathrm{O}$ High Country News é um jornal excelente. Em geral, oferece a melhor leitura do Oeste atualmente disponível, e os pontos de vista nele presentes náo são necessariamente aqueles de seus editores. Eu náo busco aqui justificar a degradação resultante da indústria madeireira, da pecuária e da mineiração, mas a maior parte da cobertura jornalística de tais indústrias é implícita ou explicitamente uma denúncia das próprias indústrias e de seus trabalhos e náo apenas do dano específico por eles causado. Ver, por exemplo, High Country News, edição de 13 jun. 1994.
} 
lazer e esconder as consequências ambientais de seu próprio trabalho, incitaram o ataque contido no adesivo de carros de Forks. Para evitar isso, e talvez até mesmo para encontrar aliados entre pessoas desnecessariamente transformadas em inimigas, é necessário que haja alguma tentativa no sentido de reconciliar-se com o trabalho. $\mathrm{O}$ trabalho não previne os danos causados ao mundo natural - a própria cidade de Forks é uma evidência disso, mas se o trabalho não for desvirtuado como um meio de converter lugares em propriedade, pode nos ensinar o quanto nosso trabalho e o trabalho da natureza estão entrelaçados.

E caso não nos reconciliemos com o trabalho, se ignorarmos as implicaçôes de nosso trabalho e de nossos corpos no mundo natural, entáo voltaremos a patrulhar as fronteiras. Transformaremos terras públicas em um playground público; consideraremos equivalentes terras selvagens e jogos bruscos; imaginaremos a natureza como um refúgio, como um lugar no qual podemos nascer novamente. Será um paraíso no qual poderemos deixar o trabalho de lado. A natureza terminará por parecer, em grande parte, uma Disneylândia orgânica, exceto que será muito mais difícil encontrar uma vaga para estacionamento.

Há, também, um corolário inevitável para essa forma particular de autoengano. Nós nos condenaremos a passar a maior parte de nossas vidas fora da natureza, já que não pode haver um lugar permanente para nós dentro dela. Tendo demonizado aqueles cujas vidas mesmas são testemunho da complexidade de um planeta onde nós matamos, destruímos e transformamos como condição necessária para nele viver e trabalhar, nós corremos o risco de reivindicar uma inocência que é, no fim das contas, mera irresponsabilidade.

Se, por outro lado, o ambientalismo puder se concentrar em nosso trabalho ao invés de se concentrar em nosso lazer, então toda uma série de novos e criativos pontos de vista sobre o mundo poderia surgir. Isso nos conecta uns aos outros, e nos conecta à natureza. Reúne questôes tão diversas como a segurança do trabalho e pastagens em terras públicas, os sítios tóxicos e as áreas selvagens. Ao assumirmos a responsabilidade pelas nossas próprias vidas e trabalho, revelando as conexóes entre nosso trabalho e o trabalho da natureza, desistindo de nossa inútil fixação com a pureza, nós poderemos finalmente encontrar uma forma de romper com os limites que aprisionam tanto a natureza como nós mesmos. É pelo trabalho, portanto, que devemos começar.

\footnotetext{
* “Are you an environmentalist or do you work for a living?”: work and nature. In: CRONON, William (Ed.). Uncommon ground: rethinking the human place in nature. Nova York; Londres: W. W. Norton, 1995. p. 171-185. Tradução a cargo de Daniel Dutra, mestrando do Programa de Pós-Graduação em História Social da Universidade Federal do Rio de Janeiro, com revisão de Lise Fernanda Sedrez, professora da UFRJ. A tradução é um projeto coletivo dos membros do Laboratório de História e Ecologia do Instituto de História/ UFRJ, coordenado pelos professores Lise Sedrez e José Augusto Pádua.

** Doutor pela University of Washington, EUA, e professor da cátedra Margaret Byrne de História Americana da Stanford University, EUA.
} 